\title{
Role of Biotransformation Based on Intestinal Flora in the Research and Development of TCM
}

\author{
Xin Li and Yufeng Liu* \\ School of Pharmaceutical Science, China
}

*Corresponding author: Yufeng Liu, School of Pharmaceutical Science, China.

Received Date: November 26, 2018

Published Date: December 03, 2018

\section{Introduction}

Traditional Chinese Medicine (TCM) is of great significance to the research and development of new drugs due to its various active components. Meanwhile, as the focus of current research, biotransformation greatly stimulates the investigation of TCM. Intestine is the primary place for the metabolism of oral drugs in the human body, where a number of parasite bacteria flora play an inevitable role in the biotransformation of drugs. Thus, it is obviously that the biotransformation based on intestinal flora is a powerful tool in the development of TCM.

There are four situations after the oral administration of TCM: first, the original formation of active ingredients of TCM is absorbed and exert their pharmacological effects; second, the metabolites of original active ingredients, which transformed by intestinal bacteria, are absorbed by human body and then generate the pharmaco

logical effects; third, the active ingredients of TCM in the intestinal tract regulate the environmental balance of intestinal flora; last, TCM is excreted with feces. Obviously, the second situation should be stressed in the biotransformation of TCM.

In recent years, the biotransformation of TCM in intestinal bacteria mainly focuses on the investigation of the metabolism of its active ingredients including Glycosides, Alkaloids, Flavonoids, Phenylpropanoid and Organic Acids, etc. The transformation of these compounds in intestinal flora often results in various consequences, such as the increasing of bioavailability, the improvement of pharmacological effect and the reduction of toxicity [1]. Therefore, the biotransformation of intestinal bacteria is a necessary method for the functional mechanism of Chinese medicine. All of the studies related to the investigation of the biotransformation of the active ingredients are listed in Table 1.
Table1: Research of biotransformation on different active ingredients in Chinese medicine.

\begin{tabular}{|c|c|c|}
\hline $\begin{array}{c}\text { Active } \\
\text { Ingredients }\end{array}$ & Substrate & Intestinal Flora \\
\hline \multirow{16}{*}{ Glycosides } & Paeoniflorin & $\beta$-glucosidase; \\
\hline & & $\beta$-glucoesterase; \\
\hline & & Digestive streptococci; \\
\hline & & Bacteroides fragilis; \\
\hline & & Lactobacillus brevis \\
\hline & Senna & $\beta$-glucosidase \\
\hline & Glycyrrhizin, & Bacillus GLH \\
\hline & Aescin & Human fecal flora \\
\hline & Centella & Asiatica \\
\hline & Aloe-emodin & $\beta$-glucuronidase \\
\hline & Gentiopicroside & Human fecal flora \\
\hline & Genipin & $\beta$-glucosidase \\
\hline & Molophane glycosides & Rat fecal flora \\
\hline & Syringin & Rat fecal flora \\
\hline & Ophiopogon & Saponin \\
\hline & Saikosaponin & Bifidobacterium \\
\hline \multirow{9}{*}{ Alkaloids } & Aristolochic acid & Human fecal flora \\
\hline & Aristolochic acid I & Human fecal flora \\
\hline & Oxymatrine & Human fecal flora \\
\hline & Aconitine & Bacteroides fragilis; \\
\hline & & Clostridium butyricum; \\
\hline & & Klebsiella pneumoniae \\
\hline & $\begin{array}{l}\text { 16-0-demethyldeoxy } \\
\text { aconitine }\end{array}$ & Human fecal flora \\
\hline & Scopolamine & Rat fecal flora \\
\hline & Atropine & Rat fecal flora \\
\hline
\end{tabular}




\begin{tabular}{|c|c|c|}
\hline \multirow{13}{*}{ Flavonoids } & Baicalin & $\beta$-D-glucuronidase \\
\hline & Anthraquinone & Human fecal flora \\
\hline & Hesperidin & Human fecal flora \\
\hline & Puerarin & Human fecal flora \\
\hline & Soybean glucoside & Rat fecal flora \\
\hline & $\begin{array}{l}\text { Quercetin-3 } \\
\text {-rhamnoside }\end{array}$ & \\
\hline & $\begin{array}{l}\text { Kaempferol-3 - } \\
\text { rutinoside }\end{array}$ & Rat fecal flora \\
\hline & Apigenin & \\
\hline & Apigenin & Rat fecal flora \\
\hline & Puera & Sinensis \\
\hline & Rutin & Aspergillus \\
\hline & Hirudin & Rat fecal flora \\
\hline & Icariin & $\begin{array}{c}\text { Streptococcus; } \\
\text { Enterococcus; Brouser }\end{array}$ \\
\hline \multirow{7}{*}{$\begin{array}{l}\text { Phenyl } \\
\text { propanoids }\end{array}$} & Purpura & Sinensis \\
\hline & Burdock & Aglycone \\
\hline & Flaxseed & Lignans \\
\hline & Bacteroides & $\begin{array}{c}\text { Bacillus; Mycelium mucus; } \\
\text { Lager Aegis }\end{array}$ \\
\hline & Mata resin alcohol & Human fecal flora \\
\hline & $\begin{array}{c}\text { Open-looped larch } \\
\text { lignin }\end{array}$ & Human fecal flora \\
\hline & Silymarin & Mucilage ZL-II \\
\hline \multirow{3}{*}{ Organic Acids } & Rhein & $\begin{array}{c}\text { Pseudomonas strain } \\
\text { RHEIN-1 }\end{array}$ \\
\hline & Shikimic acid & Escherichia coli mutant \\
\hline & Chlorogenic acid & Human fecal flora \\
\hline
\end{tabular}

Glycosides often have various pharmacological effects, such as antibacterial, antiviral, anti-inflammatory antiepileptic and so on [2]. However, they are not easily absorbed in the intestine due to the glycosyl in their structure. Moreover, the low bioavailability decreases the pharmacological activities. Fortunately, recent pharmacokinetic studies have proved that the glycosyl of most glycosides can be removed and transformed to the aglycone via the metabolism of the intestinal flora $[3,4]$. Taking paeoniflorin as an example, the active ingredient of paeoniflorin is a bicyclic monoterpene glycoside compound so that is hard to be absorbed directly. After catalyzed by $\beta$-glucosidase, its metabolites can exert antiepileptic and anticonvulsant effects [5].

Alkaloids are a class of nitrogen-containing organic compounds that have good pharmacological activities in terms of immune function, antibacterial, antiinflammatory, and anticancer effects [6]. Some alkaloids may have toxic side effects, such as diester aconitine, which shows a high toxicity. However, the molecule is easily dehydrated and hydrolyzed by the intestinal flora, which metabolites such as monoester type and lipid alkaloids to reduce toxicity $[7,8]$.

Flavonoids is kind of polyphenolic compounds which widely present in plants. Most of flavonoids are in the form of glycosides while others exist in free form [9]. According to recent studies, most flavonoids in the gastrointestinal tract can convert into phenolic acid via the intestinal flora and then absorbed by the human body. For example, Liu et al. [10] used in-vitro cultivated intestinal bacteria to transform baicalin and found that $\beta$-D-glucuronidase existed in bacteria could convert baicalin into baicalein, which has antibacterial, antiinflammatory and other effects.

Phenylpropanoids generally contain a lactone structure, mainly including phenylpropionic acid, coumarin, and lignans. The transformation of intestinal flora can induce the hydrolysis or demethylation of the lactone structure of Phenylpropanoids. Therefore, we could suppose that the biotransformation of intestinal flora might be benefit to the structural modification of drugs.

Organic acids refer to a group of acidic compounds containing a carboxyl in their molecular structure. Most TCMs with sour taste contain such components. Organic acids have a wide range of pharmacological effects, such as antiinflammatory, analgesic, antiviral, antituberculosis, inhibition of platelet aggregation and induction of tumor cell apoptosis. A large number of studies have shown that chlorogenic acid is metabolized by the intestinal bacteria after oral administration and gained pharmacological activity [11].

To summarize, the biotransformation of the intestinal flora is an inseparable part of the metabolism of drugs in the human body and can be actively applied to the research and development of TCM. This technique can greatly accelerate the process of the modernization of Traditional Chinese Medicine, such as the studying of metabolism mechanism, the optimization of the structure, the decreasing of the toxicity, the improving of the absorption and so on. Therefore, it is of great practical significance to promote the research and development of TCM.

\section{Acknowledgement}

This study was funded by grants from the National Natural Science Foundation of China (NO.81403177).

\section{Conflict of Interest}

No conflict of interest

\section{References}

1. Men W, Chen Y, Yu-Jie LI, Yang Q, Weng XG, et al. (2015) Research Progress of Biotransformation on Effective Ingredients of Chinese Medicine Via Intestinal Bacteria. Chinese Journal of Experimental Traditional Medical Formulae.

2. KoBASHI K, Teruaki AKAO (1997) Relation of intestinal bacteria to pharmacological effects of glycosides. Bioscience and Microflora 16(1): 1-7.

3. Chen Y, Jia X-b, Tan X-b, Fan C-y, Cai Y, et al. (2010) Influence of Rat Intestinal Hydrolase on Dispose of Flavonoids in Herb Epimedii [J] Chinese Pharmaceutical Journal 45(7): 516-519.

4. Tan G (2018) Biotransformation of glycosides in herbal medicine by gut microbiota. World Chinese Journal of Digestolog 26(4): 221-227.

5. Hsiu SL, Lin YT, Wen KC, Hou YC, Chao PD (2003) A deglucosylated metabolite of paeoniflorin of the root of Paeonia lactiflora and its pharmacokinetics in rats. Planta medica 69(12): 1113-1118. 
6. Lu JJ, Bao JL, Chen XP, Huang M, Wang YT (2012) Alkaloids isolated from natural herbs as the anticancer agents. Evidence-Based Complementary and Alternative Medicine 2012(5): 1-12.

7. Sun Y, Zhang HG, Shi XG, Duan MY, Zhong DF (2002) Study on metabolites on aconitine in rabbit urine. Yao Xue Xue Bao 37(10): 781-783.

8. Zhao Y, Song F, Guo X, Liu S (2008) Studies on the biotransformation of aconitine in human intestinal bacteria using soft-ionization mass spectrometry. Chemical Journal of Chinese Universities 29(1): 55.
9. Narayana KR, Reddy MS, Chaluvadi MR, Krishna DR (2001) Bioflavonoids classification, pharmacological, biochemical effects and therapeutic potential. Indian journal of pharmacology 33(1): 2-16.

10. Liu LW, Lei SI, Ren SY (2012) Biotransformation of Bacicalin by Human Intestinal Bacteria. Natural Product Research \& Development 24(10): 1437-1401.

11. Sato Y, Itagaki S, Kurokawa T, Ogura J, Kobayashi M, et al. (2011) In vitro and in vivo antioxidant properties of chlorogenic acid and caffeic acid. International journal of pharmaceutics 403(1-2): 136-138. 